\title{
An Electrical Conductivity Method for Axial Gas and Solid Holdup Determination in Three Phase Fluidized Beds
}

\author{
B.S.V.S.R. Krishna
}

\begin{abstract}
Fluidization is an operation in which solid particles are kept under suspension supported by the upward flow of liquid/gas phase. In classic fluidization the solids density are higher than the liquid, where as in Inverse fluidization the solids density are lower than that of continuous liquid phase. The phase holdup measurements in three phase classic/inverse fluidized beds are very important and difficult to measure. The phase holdups can be estimated with the help of pressure drop data and height of the bed/solids mass balance with an assumption of axial uniform solid holdup. In most of the fluidized bed operations, such as Catalytic fluidized bed and slurry bubble columns the solids holdup varies axially. Such type of systems, holdups estimation is very difficult. The present study is focused on electrical conductivity method to get directly the cross sectional liquid holdup and pressure drop to solve the above problem of axial solid holdup variation and can readily be obtained the cross sectional three phase holdups.
\end{abstract}

The averaged normalized conductance and the liquid holdup are related with liquid conductivity with a power law mode of equation. The dependency of conductivity on liquid also varies with electrode size and non-conducting medium (gas/solid). The experimental results showed that the conductivity method developed in this work was convenient for use and had a good accuracy in a wide range of liquid holdup (0.4 to 1) in the Gas-Liquid-Solid three-phase fluidized bed systems. The effect of temperature on conductivity of liquid phase was also verified and successfully correlated.

Keywords--- Fluidize Bed, Conductivity, Three Phase Holdups, Power Law Relation, Temperature Effect

\section{INTRODUCTION}

$\mathrm{T}$ HREE phase fluidized beds are widely used in process industries. The solids are kept under suspension by the upward liquid and or gas phase. The liquid forms as continuous phase while gas and solid are dispersed. Though these are widely used in process industries, design of such reactors is complicated due to the following factors axial variation of various properties i.e phase hold-ups, effective density. At high liquid and or gas flow rates these variations are very important. For example slurry bubble columns are used widely in process industries where the size variation of catalyst is very high. The catalyst is axially distributed non

B.S.V.S.R. Krishna, Associate Professor, Department of Chemical Engineering, Manipal Institute of Technology, Manipal University, Manipal576104, India. E- mail: krishna.bandaru@manipal.edu uniformly due to the size variation. Many researchers have used the following equations to determine the phase holdups in three phase fluidized beds

$$
\begin{aligned}
\frac{d P}{d z} & =\left(\varepsilon_{g, c s} \rho_{g}+\varepsilon_{l, c s} \rho_{l}+\varepsilon_{s, c s} \rho_{s}\right) g--(1) \\
\varepsilon_{s, c s} & =\left(M_{s} / A H \rho_{s}\right) \\
\varepsilon_{g, c s} & +\varepsilon_{l, c s}+\varepsilon_{s, c s}=1
\end{aligned}
$$

Where the bed height in equation (2) is visually observed. At low and high liquid /gas flow rates neither method is satisfactory. At the same time, the apparent density or solid size is sufficiently small, the axial distribution further complicates the measurement.

\section{CONDUCTIVITY METHOD}

For providing an alternative solution to the above problem, many authors tried various techniques such as optical fibre, electrical conductive probe, process tomography, staticpressure, ultra sound and isokinetic separation [1]. Out of these methods, the electrical conductivity method has advantages such as simplicity of construction \& operation, accuracy of measurement, negligible hydrodynamic disturbance, no requirement of phase modification and measurement of local phase holdups. Indirect measurement requiring prior calibration and dependency on spatial distribution of the phases are the minor disadvantages of the electrical conductivity method. Present author has used the electrical conductivity technique due to the above advantages. The principle of the electrical conductivity method is that, the effective conductivity of a suspension depends on the fraction of conducting phase in the suspension. Though different theoretical expressions exist for the effective electrical conductivity of a solid-liquid suspension [2], it is preferable to calibrate the electrodes for the particular geometry that is being used. The calibration procedure adopted here is the same as that following authors [3],[4],[5],[6],[7].

The electrodes were calibrated using the liquid holdup data (calculated using bed height) of 2-phase fluidized bed obtained for different particle characteristics over wide range of liquid velocity. The 2-phase conductance measured at each electrode covered by the bed was normalized by the conductance measured by the corresponding electrode for pure water. The normalized conductance was averaged over the length of the bed for uniform holdups else the local 
conductance was used for local holdups as shown below equations.

$$
\begin{gathered}
\gamma=\frac{1}{H} \int_{0}^{H}\left(\frac{\Gamma_{l o c}}{\Gamma_{l o c}^{0}}\right) d z \\
\gamma_{l, \mathrm{cs}}=\frac{\Gamma_{l o c}}{\Gamma_{l o c}^{0}}
\end{gathered}
$$

Similarly, data were taken for different liquid flow rates (different void fractions), static bed heights and particles of different diameters and densities. The entire data was fitted using a power law relation as mentioned in the literature

$$
\varepsilon_{l, c s}=\gamma_{l, c s}^{m}
$$

Here the parameter ' $m$ ' depends on particle size at constant temperature. The value of $m$ lies within the range (0.67 to 1$)$ as reported in literature [2].
The conductivity of a liquid-solid suspension is expected to be dependent only on the solid fraction and temperature of the system. Nevertheless, due to the finite size of electrodes used, the size of the particles has an effect on the conductivity

and the liquid conductivity also depends on temperature. Hence the present study focused on measuring the local holdups by conductivity method and to find the effect of temperature on conductivity.

\section{EXPERIMENTAL}

The schematic diagram of experimental setup is shown in Fig 1 . The column is made up of acrylic material with an internal diameter of $8.9 \mathrm{~cm}$ and a height of $2.75 \mathrm{~m}$. A one inch hole was provided at middle of the column for loading and unloading of particles.The liquid was pumped through rotametersfrom the bottom of the column where it is distributed in heat exchanger type distributor[8].

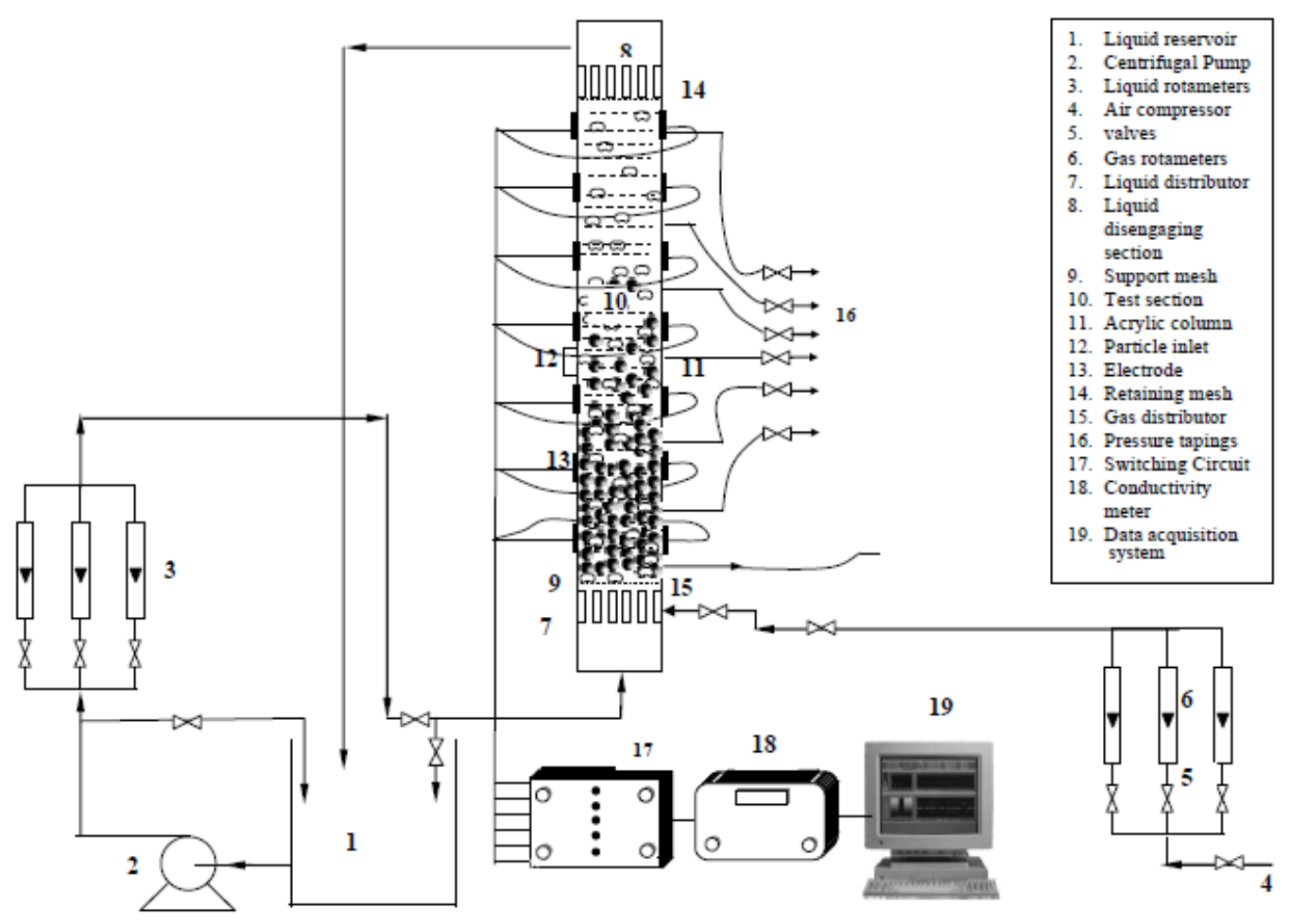

Fig.1 Schematic Diagram of Experimental Setup

Figure 1: The Schematic Diagram of Experimental Setup

Calibrated rotameters are used for measuring gas flow rate and it is dispersed at the bottom of the section. Perforated plate with $1.5 \mathrm{~mm}$ holes of triangular pitch is used as gas distributor. In test section a mesh was provided at the bottom for providing support to particles another mesh also provided at the top to prevent particlecarryover. Water, air and spherical polypropylene solid particles were used as liquid, gas and solid phases respectively. Here the liquid or water is conducting material and gas and solid particles are nonconducting materials.
Equally spaced pressure tapings were mounted on the column wall from bottom gas distributor to top particles retaining mesh. The pressure taps are connected to vertical manometer. Eighteen electrodes (stainless steel $2 \mathrm{~cm}$ x $1 \mathrm{~cm} \mathrm{x}$ $1 \mathrm{~cm}$ ) centered between the pressure taps were fixed to the column for measuring the cross sectional phase holdups [4],[5]. The electrode sectional view was shown in Fig 2. A sequential switching circuit connects the conductivity meter sequentially to the electrodes and the DC output of the meter given to the data acquisition system 


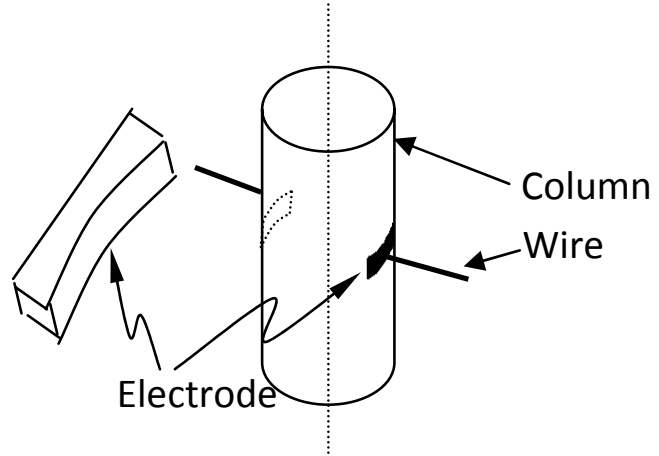

Figure 2: The Schematic Arrangement of Electrode

In the present work, the electrodes were calibrated in the 2phase to convert the conductance (proportional voltage) data to void fraction. For a chosen particle and bed height, the liquid-solid system was allowed to reach steady state for a particular liquid flowrate and the expanded bed height was noted. The void fraction is calculated using the formula

$$
\varepsilon=1-\frac{\left(1-\varepsilon_{0}\right) H_{0}}{H}
$$

The liquid holdup by conductivity method and bed height method was obtained for various flow rates and data was correlated successfully in the form of power law equation as discussed in the above section.

\section{RESUlTS AND DisCUSSION}

The effect of temperature on liquid conductivity was shown in Fig 3a. A sample of 10 data points for each electrode has shown in the Fig 3a out of 150 data points for each electrode. The averaged data (average of 150 data for each electrode) is also shown in Fig 3b.

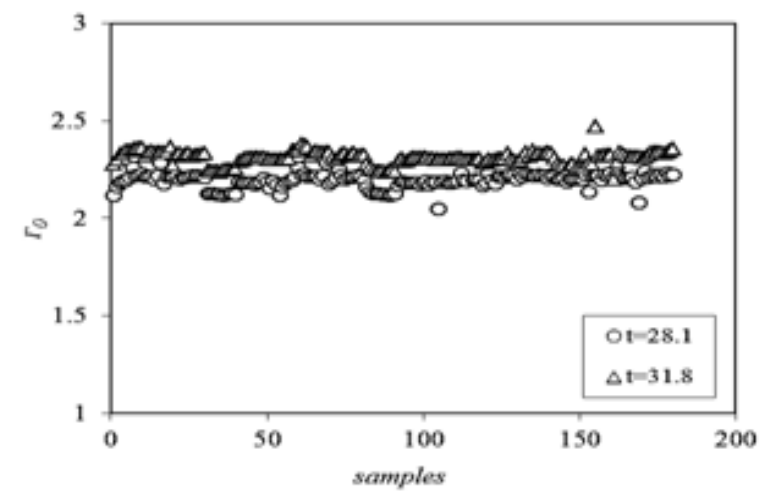

Figure 3a: Effect of temperature on conductivity of tap water (sample raw data)

It is clearly evident that from the figure $3 a$ and $3 b$ that the conductivity is increasing with increase in temperature. This is probably due to the increase in the activity of ions or salts present in the water. Same trend is observed for a wide range of temperatures $\left(25^{\circ} \mathrm{C}\right.$ to $\left.41{ }^{\circ} \mathrm{C}\right)$.

The change of conductance is approximately $2 \%$ for each 1 ${ }^{0} \mathrm{C}$ change in the liquid temperature. The probability of error may be high if the estimation can be done for high range of temperatures.
Once the effect of temperature is identified and correlated, the conductivity data collected various liquid flow rates as explained in experimental section along with nonconducting(particles and/or gas bubbles) material.

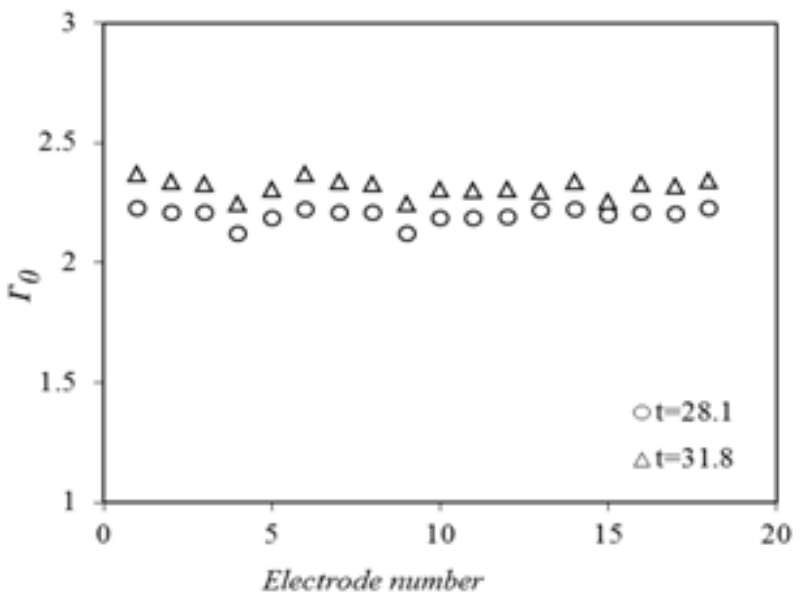

Figure 3b: Effect of Temperature on Conductivity of Tap Water

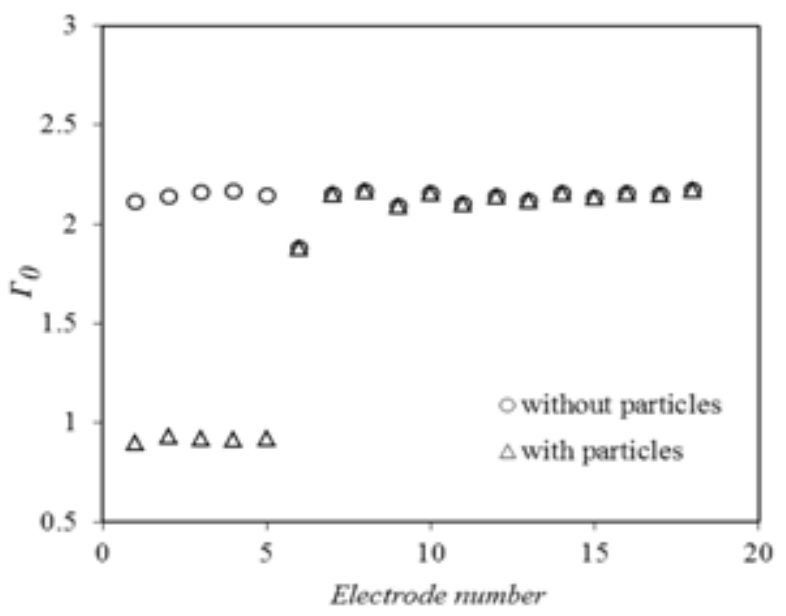

Figure 4: Variation of Conductivity with Particles and Without Particles

The variation of conductivity of the pure liquid and in the presence of non-conducting material (particles or gas bubbles) is shown in Fig 4. It is evident that the presence of particles decreases the conductivity till the $5^{\text {th }}$ electrode, $6^{\text {th }}$ electrode was covered partially with non-conducting material (particles) and a steep increase from $7^{\text {th }}$ electrode shows single phase of liquid presence alone. Figure 5 is compared the data of conductivity and the transformed data as the liquid holdup present in that each electrode. The liquid holdup was calculated with help of equation 6 by using the relative conductivity. The constant ' $\mathrm{m}$ ' in the equation (6) depends on non-conducting material size (size of particles/ size of air bubble). 


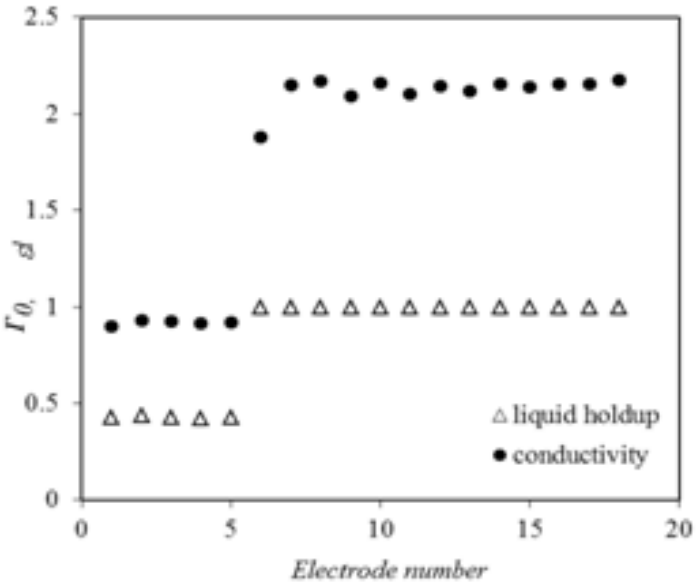

Figure 5: Comparison of Conductivity with Liquid Holdup for Two Phase Liquid and Solid Fluidized

Present study found that the $m=0.727$ for particles of diameter between $0.180 \mathrm{~mm}$ and $2.89 \mathrm{~mm}$ and $m=0.877$ for particles of diameter between $5 \mathrm{~mm}$ and $8 \mathrm{~mm}$. The above values are with-in the range [2].Above procedure was adopted for obtainingthe liquid holdup for various flow rates of liquid/gas.

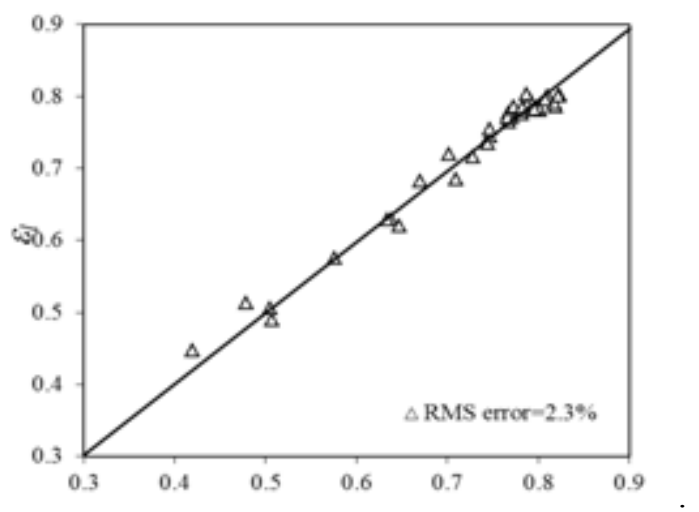

Figure 6: Comparison of Predicted and Estimated Liquid Holdup for 3 Phase

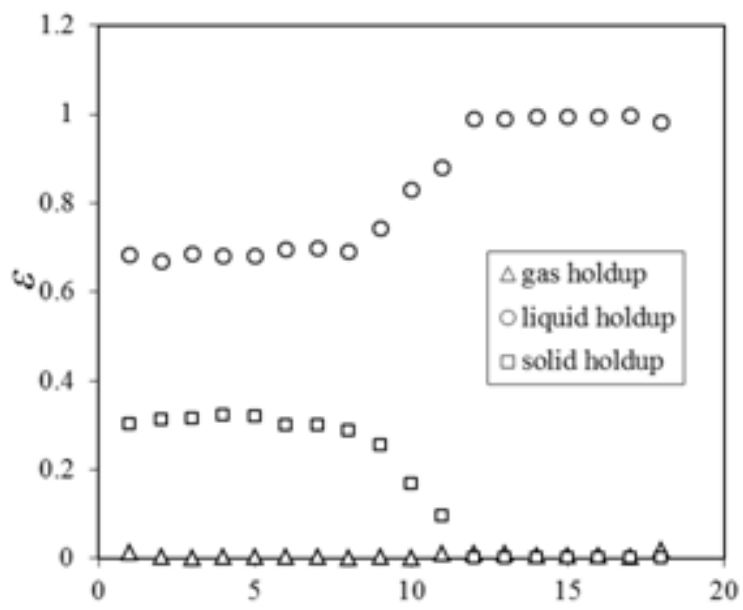

Figure 7: Variation of Gas-Liquid- Solid Holdup in Three Phase Fluidized Bed

The liquid holdup calculated based on conductivity from equation (6) and bed height measurement of equation (7) is compared in Fig 6 for two phase flow of liquid and solid. The data was well correlated with an RMS error of $2.3 \%$.

Figure 7 shows the axial variation of Gas-Liquid-Solid holdup. One can observe a clear axial variation of solid-liquid holdup change from the fluidized bed region to free board region. Similar observations are made in literature[3],[4],[5].

\section{CONCLUSIONS}

The following conclusions can be drawn from the study

1. Conductivity technique is successfully used for identifying the axial variation of gas-liquid-solid holdup

2. Effect of temperature on liquid conductivity showed $2 \%$ change in conductivity for one degree change in temperature for the present case.

3. A power law relation was established between the relative conductivity and liquid holdup

4. The constant ' $\mathrm{m}$ ' depends on non-conducting material. For small particles the $\mathrm{m}$ may be small and for bigger radius particles this can be high but the range of $m$ is 0.67 to 1 .

\section{NOMENClATURE}

A -cross-sectional area

$\mathrm{dP} / \mathrm{dz}$-pressure gradient

g-acceleration due to gravity

$\mathrm{H}$-Height of the bed

$\mathrm{M}$-mass of solids

$\mathrm{m}$-constant in equation (6)

Greek letters

$\varepsilon$-holdup

$\rho$-density $\left(\mathrm{kg} / \mathrm{m}^{3}\right)$

$\Gamma$-Liquid conductivity with particles

$\Gamma^{0}$-Liquid conductivity without particles

$\gamma$-relative conductivity

Subscripts

0 -static bed conditions

cs-cross sectional

$\mathrm{g}$-gas

1-liquid

loc- local

s-solid

\section{ACKNOWLEDGEMENT}

The author would like to acknowledge the help and guidance of Prof. K. Krishnaiah, Dean, Academic Research, and Dr Renganathan, Assistant professor, Dept. Chemical Engineering. IIT Madras, Chennai, India

\section{REFERENCES}

[1] Razzak, S.A., Barghi, S., Zhu J. -X. and Mi, Y., "Phase holdup measurement in a Gas-Liquid-Solid circulating Fluidized bed riser using electrical resistance tomography and optical fiber probe" Chem. Eng. Jr.147, 210-218 (2009).

[2] Tang, W. T. and L. S. Fan, "Hydrodynamics of a Three-Phase Fluidized Bed Containing Low-Density Particles", AIChE J. 35(3), 355-364 (1989).

[3] Begovich, J. M. and J. S. Watson, "An Electroconductivity Technique for the Measurement of Axial Variation of Holdups in Three-Phase Fluidized Beds", AIChE J. 24(2), 351-354 (1978). 
[4] Ibrahim, Y. A. A., C. L. Briens, A. Margaritis and M. A. Bergongnou, "Hydrodynamic Characteristics of a Three-Phase Inverse Fluidized-Bed Column", AIChE J. 42(7), 1889-1900 (1996).

[5] Renganathan, T. and K. Krishnaiah, "Voidage Characteristics and Prediction of Bed Expansion in Liquid-solid Inverse Fluidized Bed", Chem. Eng. Sci. 60, 2545-2555 (2005).

[6] Krishna, B.S.V.S.R., "Hydrodynamics of 2- and 3-phase Inverse Fluidized bed with mono and binary particles", Ph.D. Thesis, IIT Madras, Chennai, India (2006).

[7] Krishna, B.S.V.S.R and K. Krishnaiah, The Minimum and Uniform Fluidization velocity of Inverse Fluidized bed", Int. J. Chem. Sci., 5(4), p1733 (2007).

[8] Fan, L.-S.,K. Muroyama and S.-H. Chern, "Hydrodynamic Characteristics of Inverse Fluidization in Liquid-Solid and Gas-LiquidSolid Systems", Chem. Eng. J. 24, 143-150 (1982). 